\title{
The Unheard, the Unspoken, A Phenomenological View of Deafness
}

\author{
Irum Maqbool $^{1 *}$
}

\section{ABSTRACT}

Pakistani society is predominantly Hearing. Almost all facilities are provided to the hearing community. Current study is an Endeavour to understand the world-view of Deaf. Participants are school-aged adolescents, Deafness has been studied from a phenomenological perspective, and for data triangulation the teachers of the eight participants were also interviewed. Students and the teachers reported low communication with society as well as with parents, sign language is seldom learnt by significant others and the children feel isolated in a world of their own. Dislike of the hearing community was widespread, limited resources have led to alienation from the hearing society around them. Within the deaf community a feeling of oneness and similarity prevails which in some cases was advantageous and helped build a strong self-esteem whereas in other cases a source of anger for children who felt helpless. Areas used to build on in the research range from social functioning to coping in the hearing world. The aim of this study is to provide insight into deafness while at the same time build insight among the hearing community, in order to level the playing field for both communities and advocate equality. The study offers understanding of what it means to be different, with the findings further elaborated in respects of what could be the case along with what is.

\section{Keywords: The Unheard, The Unspoken, Deafness, Pakistan}

Hearing impairment or deafness is a leading disability around the globe. Deafness ranges from mild to profound depending on the hearing loss range in decibels (American Speech-Language Hearing Association, 2011). Hearing impairment is also divided into three types depending on the part of the ear damaged. Namely, Conductive hearing loss, sensorineural hearing loss and mixed hearing loss. Sensorineural hearing loss cannot be surgically or medically treated and this is the leading type of permanent hearing impairment. Other descriptors that are of significance to define deafness include the following; bilateral hearing loss is loss in both ears, unilateral is one ear only. Symmetrical is the same loss in tones and frequencies in both ears contrary to asymmetrical loss, it is also differentiated on terms of sudden versus progressive hearing loss as well as fluctuating versus stable hearing loss (American Speech-Language Hearing Association,

\footnotetext{
${ }^{1}$ Kinnaird College for Women University Lahore, Pakistan

*Responding Author

(C) 2016, I Maqbool; licensee IJIP. This is an Open Access Research distributed under the terms of the Creative Commons Attribution License (http://creativecommons.org/licenses/by/2.0), which permits unrestricted use, distribution, and reproduction in any Medium, provided the original work is properly cited.
} 


\section{The Unheard, the Unspoken, A Phenomenological View of Deafness}

2011). It may also be pre-lingual; before the individual acquires a spoken language or postlingual which occurs after the acquisition of a language and is usually progressive. Some people are born deaf while others get it at some later point in time (American Speech-Language Hearing Association, 2011).

Deafness is not just a disability it has grown to be a way of life different from the majority population, so much that it has grown to be a kind of social identity or a community. Baker and Padden (1978) define the Deaf community as; "The Deaf community comprises those deaf and hard of hearing individuals who share a common language, common experiences and values, and a common way of interacting with each other, and with hearing people.” If we use this definition to study people who have deafness then it can be assumed that people who have hearing impairment have certain characteristics that stem from the defining factor that are different from the majority community or somehow set these people apart. Deafness has also been identified as a cause of stigmatization and discrimination; it also suggested causing economic disadvantage.

Deafness is a global issue with 360 million people affected they make up 5.3\% of world population. Of these $9 \%$ are children where as $91 \%$ are adults. In south Asia a large number of children suffer from deafness, $27 \%$ of world population of Deaf is in these areas that comprise of Afghanistan, Bangladesh, Bhutan, India, Nepal and Pakistan (World Health Organization, 2012). It is stated in the dictionary of psychology that deafness has four psychological dimensions. These dimensions affect the people with deafness and were formerly seen as deficits and now these are seen as differences or psychologists are trying to explore these dimensions. These four dimensions include; (1) acquisition of language and culturally oriented knowledge, (2) cognitive development, (3) behavioural and emotional adjustment and (4) social identity (Braden, 2000). It is these four areas that provide the framework for understanding Deaf on a psychological realm. If emotional adjustment is elaborated then it is understood that emotions define behaviours and are made by perceptions. Emotions play a great role in the formation of personality and as its building blocks. Social identity is essential since it gives one a self-concept and has deep roots as well as far reaching consequences. Self-esteem and self-concept are formed at an early age and these identities that are formed help in fitting in with the crowd. Culture and knowledge of the culture affects how people behave and as stated before can be a dimension of a psychological aspect of deafness. Hence, deafness may also have an effect on the self and the defining factors of self for the individual.

Self-esteem defined as “One's feelings of worth, it consists of the positive and negative feelings a person have about himself. It stems from the evaluation of others, as well as the extent to which the child feels successful in those areas thought to be important” (Bukatko \& Daehler, 2004). Self-esteem is mainly thought to evolve and be of considerable importance from third grade to the eighth grade. This self-esteem emerges by comparing oneself to others around them. Selfesteem is an individual and social phenomenon. It is also found that during the age of eight to

(C) The International Journal of Indian Psychology, ISSN 2348-5396 (e)| ISSN: 2349-3429 (p) | 108 
twelve children tend to form friendships and wish to avoid the insecurity that peer rejection brings also they have a need for acceptance that is fulfilled by peers and those around them. Thus, during the middle school ages of roughly eight to twelve self-esteem builds and rejection is avoided (Bukatko \& Daehler, 2004). So the child starts of his or her journey as a social member of the society they live in and this group behaviour builds the framework for a dynamic society. It is at this age that the two stages proposed by Erikson overlap as well; the industry vs. inferiority stage as well as Identity vs. role confusion. During the former children have to cope with a variety of academic and social challenges competence in with lead to high esteem whereas failure can lead to feelings of inferiority, this extends from age 6 to 11. The second stage knows one's place in the world at large and forming an identity, this lasts from 12 to 18 years(William, 2011). Thus, during the age of eight to twelve or up till the end of school a variety of social and individual traits and characteristics are formed and moulded.

The children who cannot hear are more than often labelled deaf however; the experience of being deaf in a hearing world is seldom shared. A review of literature also suggests that a lack of information persists in this area of physical disability. The current study aims at gaining an indepth perspective of living with deafness in a society that is not disability-friendly, where resources are scarce and education levels remain low. The study aims to find out the differences or similarities in experiencing deafness and how children make their place in an all-hearing society also their perspective on hearing people, along with coping skills and its impact on their self-esteem and group identification.

\section{LITERATURE REVIEW}

Various researches have been conducted in a number of societies regarding the Deaf from multiple perspectives. Research on the Pakistani society of Deaf however has largely focused on academic and educational perspectives.

Research shows that deaf students had self-esteem comparable to that of hearing students and the differences could not be caused by deafness. Identification with the Deaf community causes higher self-esteem, also being bicultural (part of the hearing and Deaf culture) leads to higher self-esteem. Research shows that Deaf community helps identification and causes group formation (Jambor \& Elliot, 2005).

Literature is available on how the family deals with deafness also how it affects family life. A comprehensive review of literature suggest that four domains of family life that are most affected include; family quality of life, including family interaction, family resources, parenting, and support for the child who is deaf. Hence, research suggests that it is not just the child who undergoes an experience it is one that the entire family goes through (Hardonk, Desnerck, \& Loots, 2011). Study on university students in Pakistan finds that the teachers are not wellequipped when it comes to teaching resources for deaf students. Students who are deaf miss out 


\section{The Unheard, the Unspoken, A Phenomenological View of Deafness}

on information in the classroom. Very little people around them in university try to adapt to their way of learning and mostly they are left out to fend for themselves. Specific tools for teaching deaf are not available to the teaching staff; sign language is also not learned by the teachers most of the time (Safder , Muhammad, Akhter, Fatima, \& Malik, 2012). Another study on inclusive education practices suggest that the student ends up being isolated rather than integrated. The classroom practices are not tailored to meet the needs of the different students and the deaf children have to keep pace with others. This can also lead to confusion and limited growth (Asif, 2008).

Research conducted in Uganda shows how various identities are a source of restraint rather than an enabler in a diverse society. As well as the fact that the deaf and hearing impaired are placed far apart in the third world societies compared to the western developed world (Mugeere, Atekyereza, Kirumira, \& Hojer, 2015). Research conducted in the UK shows that people negotiate identities on a multiple backdrop. The identity claims are complex and contingent; they are also dependent on the resources available and play a crucial role in the legitimisation of these. The population of this study mostly included people of Pakistani origin. This study found that deafness may not be the only factor; other bases of identity are equally important ( Ahmad, Atkin, \& Jones, 2002).

Research shows that Ghana is not disability friendly. The society discriminates against people who are deaf. People with disabilities are often marginalised this leads to lack of self-esteem and low self-image in the person. The problems that exist within the society are due to implementation of policy. This lack of participation in society and lack of control in personal life leads to feelings of inferiority (Nortey, 2009). Curriculum planning and teaching are also difficult for teachers when it comes to deaf population. Research conducted in Pakistan shows that teaching mathematics is difficult for teachers and there are not many additional teaching resources at their disposal (Fatima \& Malik, 2015). A number of researches have been conducted on cochlear implant. Current research does not specifically focus on cochlear implant students. Research however shows that cochlear implant increases the likelihood of adjustment, difficulty following conversations however remained (Preisler, Tvingstedt, \& Ahlstrom, 2005). Research shows that as far as coping mechanism are concerned deaf wish to act normal with hearing people and they try to prevent the definition of deviant as much as they can especially when interacting with hearing people (Lillemor, Hallberg, \& Carlsson, 1991). Children with good oral skills are also found to be good signers. Quality of peer interaction, use of sign language, communicative style of the adult and other factors were found to be important factors in communication with children with cochlear implant (Preisler, Tvingstedt, \& Ahlström, 2002). Another research with deaf people worked towards shedding stereotypes. The research interviewed successful deaf people and the participants also made recommendations for their peers. The purpose of the study was to portray deaf in a positive light unlike the negatives that are usually focused on (Luckner \& Stewart, 2003). A study conducted with a small sample 
indicated that cyberbullying and cyber victimisation is of equal incidence for deaf and hearing children. The study also found that the incidence of conventional bullying was similar (Bauman \& Pero, 2011). Research shows that coping methods can improve the situation and help the social and psychological aspects of the individual especially the isolation felt. Research conducted on twenty-three students who were deemed highly exceptional by their schools indicates that in the face of stressful situations positive coping methods were available to the students and they made use of these good coping skills (Charlson, Strong, \& Gold, 1992). Early support for families of deaf is very important. The support should be oriented towards providing resources to the child and family. Otherwise parental stress is associated with socioemotional problems of children (Hintermair , 2006). Family involvement is also significant in language development. Research indicates that family involvement in early intervention leads to successful language development however if the enrolment to intervention is late or family involvement is low the child suffers delayed language development (Moeller, 2000). Another study on language development gathered data from sixteen students and analysed it using phenomenological approach. It focused on students learning American Sign Language using online resources. It found that students often thought that the teachers were not well-equipped and needed better training to increase functioning in a number of other areas. They did however find that some designed software increased post-secondary education (Wooten, 2014).

\section{METHODOLOGY}

Research Design:

Qualitative Research; which focuses on the people and their experiences rather than the number of responses required for generalization.

\section{Sample:}

Sample consists of eight children who experience 'deafness'. The children were selected using the 'gatekeeper' approach to data collection in qualitative research. The children chosen for this study went to the same school, located in the heart of Lahore, Pakistan. This school was chosen for 'maximum variation sampling'. The school is a non-profit organisation; it caters to people of all walks of life. The school reports admitting students from upper as well as lower socioeconomic class, both genders were admitted along with children with varying degrees of deafness. The school has its own buses that provide transportation facilities to all its students. The teachers are well-versed in teaching methodology for the Deaf. Teachers are regularly trained and the speech-therapist was also found to be working with a broader organisation, with an aim to work at the national level, for the development and promotion of indigenous sign language curriculum.

In order to make the sample and data as diverse as possible both genders, male and female, were selected. Three students had good speech, could be comprehended easily. Two of the students were females whereas the rest were males. All of the students interviewed needed sign language 


\section{The Unheard, the Unspoken, A Phenomenological View of Deafness}

for two-way communication. Students selected were in the Secondary school, only one was in High school. The reason behind selecting this particular age group was that they can better report their experience compared to children younger to them. The age range of the eight students interviewed is from 13 to 18 years.

The teachers were interviewed for data triangulation. Teachers were chosen after a preliminary interview with a parent and a family member of one deaf child, the responses of these two people and a social worker indicated that the teacher is a better informant for school going children who are deaf, the communication was more frequent and the teacher also served as a translator between parents and child. All teachers of the eight students were females; they were also their class-teachers.

\section{Data Collection Method and Procedure:}

The tool used for data collection was an in-depth interview. The interview with students was conducted with the aid of an interpreter since knowledge of sign language is essential. Research ethics suggest that interviewing with the help of an interpreter is acceptable within the research paradigm and that other research using this method has been conducted (Young \& Hunt, 2011). The interpreter was a regular teacher at the school who had a great rapport with the students since she had taught them at the primary school level. The average duration of an interview was 45 minutes. During the interview spoken language was also used and students with hearing-aid communicated directly with the researcher as well. All interviews were conducted in the school library; during the time of the interview no onlookers or other students were present in the vicinity. The procedure of interview and the specifics of the interview process were discussed and developed further to suit the sample population by the help of two senior researchers who had extensively conducted qualitative research before.

The teachers were interviewed in the staffroom in the absence of other people in order to maintain confidentiality of the students. The teachers were all hearing and proficient in sign language as well. The average duration of an interview with the teacher was 1 hour 30 minutes. Teachers also discussed parental reports and the students overall functioning.

The students and the teachers were briefed about the research aims, their consent was formally sought, and they were also informed that they could leave at any time during the research process. The confidentiality of the students was maintained at all levels of the research process. Prior to this the approval of the school was sought and granted; the school also provided the necessary facilities for making this research possible.

\section{Data Analysis Technique:}

The interviews were audio-taped after the consent was taken from the participants. The interviews were then transcribed and coded. The method of data analysis is Transcendental 
Phenomenology focused less on the interpretations of the researcher and more on a description of the experiences of participant (Creswell, 2006). By using this methodology of investigation experience of the Deaf was analysed. Transcendental phenomenology implies that the data was analysed as an experience of the consciousness rather than interpreted, it is not a scientific method of study of data. Rather it focuses on how things come to be experienced by the ones who are living it. Textural and structural descriptions were made use of relying upon theoretical categorisation, this is a technique used in phenomenological research. For this purpose the categories and codes were bracketed and then the descriptions were integrated into themes. These themes were an outcome of not only the textual description but also the structure of the consciousness as analysed using the responses given by participants. The data was thus coded and categorised for analysis and themes were derived likewise as mentioned above. The purpose of using this particular research design is to answer questions based on interpreting deafness as a phenomenon. For validity check 2 (25\%) of the interviews from each category of participants, i.e.; students and teachers were coded by an academic external familiar with the research basic premise.

Current research made use of Moustakas' theory and practice of Transcendental Phenomenology. Epoche was employed, since no interaction of the researcher occurred with a Deaf person, no preconceived ideas existed. Relevant research was consulted only to the limit of formulating research questions and aspects to be looked in to. Results hold meaning as they will be discussed. Deafness is an experience which has been studied as a social phenomenon. All information is based on the people's experiences of living Deaf in a Hearing community. Knowledge gained from the interviews was used to arrive at conclusions and to draw meaning. Existential dimension were explored and the results are based on similarities and differences alike (Creswel, 2007).

Dialogical Phenomenology is another aspect where co-researcher or an informant is used in order to understand the meaning as portrayed by the main subjects of the study (Creswell, 2006). In the current study as well teachers were interviewed of all students in order to triangulate the findings and gaining insight into relevance or differences. This was used for empirical value with an engaged attitude.

The most relevant method of study remains to be for this research question, transcendental phenomenology, since it helps answer 'what it means to be', the fundamental basis for phenomenological study, creating meaning from experience (McLeod, 2001).

\section{RESULTS}

The findings of this study reveal various themes of deafness. The verbatim quoted here from the transcribed data are the ones that the students communicated. As mentioned earlier in the methodology an interpreter was present during the interview process, the quoted text is English 
translation of the student's experience as translated from sign language. Five out of the eight students had spoken language communication skills as well but they also made use of signs, in all of these cases language skills alone could not have been enough for communication and higher order thoughts needed sign language for articulation.

\section{Feelings about Deaf community Students}

All, except one student, like school more than they like their own homes. They generally report enjoying coming to school and waiting for school during holidays and over weekends. They report the reason behind this choice to be ease of communication and understanding each other, all their friends are in the school. Deaf community contact is limited to people they know at school, in the absence of strong ties with Deaf, communication and mutual understanding was an asset.

A 14 years old student said, "I was in a normal school before this one, but I like it here and have friends. Talking with friends here is easy using Sign language."

A 16 years old student shared her experience, "Communicating herewith friends is easier using Sign language. I am the only one Deaf at home and have no friends beyond school."

Presence of a family member with deafness also had a variety of effects. Two students reported a Deaf relative, in one case the student's sister and another one had a deaf cousin. The gender seems to affect the relationship. Similar gender helped bridge gaps and positively affected functioning at school and home. Opposite genders of the two deaf children caused low friendship.

A 16 years old girl said, "I have a girl cousin who is also Deaf, she goes to the same school and lives close by, I am fast friends with her ad we have fun together at family gatherings as well." Whereas a 13 years old boy reported, "My sister is also Deaf, I can use Signs with her, but I only communicate little with her. She has her own interests; I wish I had a brother."

One 14 years old student reported that he does not like the Deaf community and feels alien. He cannot identify with the Deaf. "I only have one friend and he is Deaf. I don't like working with the other student's here. I do not understand them."

Most of the students interviewed reported that they found Deaf more understanding and friendly. They did not tease or bully them. A 16 years old girl responded that, "people at school understand me more than people at home. They know I am a little fat since childhood and don't tease me about it. I have friends here and at home as well I use Facebook and keep in contact with them." 


\section{The Unheard, the Unspoken, A Phenomenological View of Deafness}

A 16 years old boy said, "I love coming to school I don't wish to go home. At home nobody has time for me. Here the students and teachers understand what I say, I can talk to them. I have a sister who is deaf but she left school after class five and has poor Signs."

One 13 years old boy reported that he wished he was normal and never part of the Deaf community.

\section{Teachers}

The teachers of the students who were part of this study were also interviewed and they reported similar views. Only one student has problems at school since he doesn't like the Deaf community.

One of the teachers reported, "We use stay-at-home as a punishment. It is an effective deterrent. All these children love coming to school. If we tell them they are not allowed to come to school or go in the same bus as their friends they behave properly and do not indulge in mischief. Normal schools use detention as punishment, with us it is opposite.”

Another reported, "We have a lot of parents complaining during summer vacations, they are upset and want the school to re-open. They cannot handle these children at home and the students have agitation and anger problems during long holidays."

When probed about the reasons for this all of the teachers of respective students reported the same thing; the parents did not learn Sign language.

A teacher said, "The parents do not know how to communicate with them. They do not learn sign language. There aren't enough resources and even when the school offers any a few parents are willing to come. Usually the students come from middle socio-economic class and have other children to look after as well. Social support services are lacking and they have to balance the funds."

The teacher of the girl student who has a cousin in the same school said, "She loves coming to school so much that she never has a day off! Whenever we calculate her attendance it is 100\%. She is friends with her cousin and it has also improved her academic progress. Keeping them apart is difficult, their parents say the same."

In the case of the student who reported he didn't like school the teacher added on that, "He doesn't like coming here. He misbehaves in school and has anger issues. His parents are rich and there is a lot of pressure on him or so he feels. Everyone else at home is of the Hearing community and he feels left out. He doesn't want to be here."

The teacher of 16 years old boy said, "He does not identify with either of the communities. He wants to be normal so badly that he doesn't wear the hearing aid at home; in school he has drifted away because he plays cricket with Hearing boys after school and they also bully him but 


\section{The Unheard, the Unspoken, A Phenomenological View of Deafness}

he doesn't admit it. He feels lost in school and the situation at home isn't any better. He went three months without communicating with his parents and they are also worried.”

\section{Relationship with family Students}

The second theme that arises is the relationship the students had with their family members. The responses were usually based on the relationship with immediate family, parents and siblings. Three of the students interviewed lived in joint family set-ups, where the grand-parents or an uncle lived in the same house. Students who lived in joint-family set-ups were more likely to be better adjusted, their teachers described in detail that getting attention from multiple sources made them well-rounded individuals. Certain skills such as riding a bike were better learned in the presence of a close uncle, grand-parents were a source of protection when interacting with other neighbourhood children such as playing cricket or going to the local grocery store.

Generally the children felt that their relationship with their families was lacking due to problems in communication. They had a strong desire for communicating with their parents especially but felt frustrated; only one child's mother tries to learn sign language. Low identification with siblings was also found. All eight children interviewed must be noted did feel that their parents loved them a lot, however communication problems persist and feelings and thought were not communicated and feelings of alienation existed. Communication and understanding was low.

A 13 years old boy student said, "My mother tries to explain TV shows to me. I want to talk to my parents but they do not understand Sign language. Mother is very selective in giving attention. Whenever I say something my mother asks for repetition so many times that I leave it alone. I get angry and walk out. I wish I could hear, my parents would love me more and I could be friends with my mother."

A 14 years old boy stated, "I love my parents. Their Signs are not good. I want to talk to my father but he cannot use sign language. I like talking to my brother instead, he tries to learn. Usually I get fed up when my family doesn't understand what I mean. I have stopped trying....... I walk to the grocery store with my grandfather."

Another 14 years old student who had acquired deafness in early childhood as a result of diabetes suffered from agitation at home. His younger siblings make a lot of noise and he takes his hearing aid off at home. He said, "My brother isn't friends with me, he gets disturbed when I talk to him. I only communicate with my parents a little, whatever they can understand easily. I wish they learnt sign language. My brother has his own friends, I don't know them........ I try hard to speak correctly when my father is around....they also take me to speech therapy classes...... I help my father at work during summer vacations." 


\section{The Unheard, the Unspoken, A Phenomenological View of Deafness}

A 16 years old girl said, "I feel left out during family conversations. Nobody tells me what is going on. My mother doesn’t use signs and I don’t have friends at home.”

Two students who wore hearing aid had encouraging families. They helped them with speech therapy and also encouraged the use of spoken language at home and school.

An 18 years old boy, who also use spoken language throughout the interview and only needed very little signs, said this, "My parents encourage speech.... They prefer that I converse by speaking rather than signing. However I do not understand all of the family conversations and I wish they explained all their conversations and the details to me.” Another student quoted above had an encouraging family; they regularly took him to speech therapy classes and practised at home.

Family members did not learn sign language and even in the presence of ability to speak; constant repetitions were frustrating and troublesome. Two students faced this problem and their response is quoted above.

Most of the students wished they could hear. Two of them wished this in the context of their families; they believed their relationship with the family would be better if they could understand them better.

A 16 years old girl said, "My family doesn't tell me the detail of their conversations. I wish I could hear. I have two sisters; I could be friends with them.”

Another 17 years old girl reported similar feelings, her father passed away quite a while ago and she lived with her mother, "I want to discuss things with my mother and understand what she is watching on TV. I wish I could hear, I would have been friends with my mother.... love her so much"

Children in general reported being loved at home and not scolded, but even in the presence of this they felt left out. A 16 years old girl reported, "My mother treats all of us (siblings) with love, she doesn't have one favourite.....but I wonder if I could hear I would also be included in the conversations. I want to know what the others are talking about.”

All student except one reported that no one in their family had learnt sign language or made an effort to learn it. Only one student's mother was trying to learn, he reported "She comes to the school sometimes to learn sign language from my teachers and practices at home.” This student was better at spoken language and acquired deafness during early childhood and used to attend a mainstream school before.

A 13 years old boy said, "My sister is also deaf.....she knows sign language......my parents have not learned sign language.”

A 16 years old girl reported, “My mother doesn’t know sign language.... My sisters don’t either. I am the only one Deaf in the family." 


\section{The Unheard, the Unspoken, A Phenomenological View of Deafness}

Another 16 years old reported, "Nobody in my family knows sign language.....I was friends with my elder brother but he has gone abroad now.... He calls on the telephone.....but nobody explains to me what he says because no one in the family can sign...... I want to be friends with my brother but he has never been interested"

An 18 years old student reported that his brother helps him with watching TV whenever he doesn't understand anything he explains it to him. This student could hear considerably better with a hearing aid and had good articulation of spoken language as well.

Feelings of alienation with siblings were common among all participants. As noted above a number of students reported not being friends with their siblings despite a strong desire to be. Siblings did not know sign language either and the participants felt left out.

A 16 years old boy when asked where his brothers go to school replied, "I don't know, he doesn't tell me anything. He gets agitated if I ask anything.”

Another 18 years old boy was asked where he wants to go to college after finishing school, "I want to be where my brother is." When asked further where that he was said, "I don't know, he started college two years ago, I have never been there and I don't know what he studies......he has his own friends."

A 16 years old girl added, "My brother has somewhat better sign language....but he doesn't want to talk to me and rarely answers."

\section{Teachers}

The teachers' reports on their student's relations with their families confirmed that the parents do not learn sign language. All eight of them stated that the students are closer to their teachers at school than they are to their own parents. Their parents seldom understand their needs or jokes, conversations are important. Students tend to share a lot of what goes on at home with the teachers but the parents do not know much of what goes on in school.

The parents of one girl child have never attended the parent-teacher meeting and only her eldest brother comes, even he is all the time complaining. Though the teachers reported that the parents were encouraging and some of the mothers were very dedicated, the frequency of complaints was high. Parents call up the teachers often to counsel the students regarding behavioural problems; they find it difficult to communicate with their child.

In three of the cases students attended speech therapy classes, one teacher had a unique insight on this, she said, "You know (name of child)'s parents take him to speech therapy regularly once a week. He functions normally in school and uses as much sign language as his peers. At some level I think the pressure is rising for him to learn to speak. You see his parents do not learn sign 


\section{The Unheard, the Unspoken, A Phenomenological View of Deafness}

language and he has to learn speech. He is getting more worked up day after day over learning to speak correctly. This is also causing low communication with his father. It takes him a lot of effort to articulate correctly and when the parents find mistakes he is heartbroken. It is increasing his desire to be one of them."

On communication gap and defiance teacher of a 16 years old boy said, "He doesn't listen to his parents anymore. He has adjustment issues at home. He is a sociable boy and his parents do not learn sign language, they are not educated enough themselves and have no clue how to handle him. He runs away from home and they have to lock the doors. Whenever I ask him why he does this at home he only has one answer, what should I do at home when nobody tells me anything or understands me.”

All teachers reported that their students confide in them that they feel isolated in their families and needed someone to talk to.

Teacher of a 14 years old boy stated, "His parents are well to do and the only thing they can think of for compensating for deafness is buy him this, this is not the correct parenting style, they should learn to be a part of his world instead.”

Teacher of a 16 years old boy reported, "His mother sometimes calls up to ask questions about what some signs mean, and this is good progress, but she is a unique case in this school. We don't have such parents often." She also added about another child she teaches but was not included in this study, "I have another student (name of child), his mother also wants to know signs but they are usually the ones she needs to give him commands or directions. This has further widened the gap between parents and son; I think he is drifting away, because you see they don't want to learn what he wants to say they only want him to know what they want from him."

13 years old boy who also has a deaf sister had his teacher saying this, "I don't understand his parents, his father has a hectic job but his mother is at home. Two of their children are deaf but they still haven't leaned sign language. She loves her children a lot and cooks for them, but the child wants to be heard by his mother and it is sad when he tries to find a mother in his teacher, I have seen this happen so often...."

Teacher of 16 years old boy when talking about her student's defiance and maladjustment problems had this to add, "He is a very god student and can work hard, but sometimes he feels nobody needs him and he gets destructive. This kind of anger is also a way of grieving."

The teachers view regarding the effect of socio-economic factors as the cause of neglect has been mentioned above. Two teachers reported that when they asked the parents to do more for their children, they responded by saying they were already doing as much as they could. 


\section{Perceptions of and experiences with Hearing people Students}

This theme like others varied over a spectrum, from liking the normal hearing community to hating them and envying them for having everything in life. The way in which the students coped with their feelings is a separate theme and will be discussed later. All eight participants described in detail the experiences they have had with hearing people, only a few close friends or relatives were nice to them, teasing and bullying and discrimination was felt widely.

Three students reported never being teased by hearing people, even in these cases however discrimination was felt. An 18 years old boy said, "I wear a hearing aid and I have never been teased.............I can usually hear what they say." The same person also reported this however, "Normal people keep saying you are deaf you can't understand......they never help."

A 17 years old girl stated, "I never thought that people who can hear are bad....I never compared the two."

The remaining five participants of the study reported strong dislike of the hearing community. They felt that those who can hear are at an advantaged position and are preferred by others, in one case this feeling was also held with reference to parents they were also thought to love children who could hear more.

A boy 13 years of age stated, "I hate people who can hear, they are loved by others......parents also like them more..... They enjoy life; all opportunities are available to them only."

A 14 years old boy stated, “I don't understand normal people, I have never wanted to be friends with them...........don't like them much."

Teasing by hearing people was frequently reported, in cases where it was not reported the simple answer that students gave was that they only travel with their family, this is related to the coping mechanisms theme mentioned below.

A 13 years old boy stated "Whenever I go to play cricket with the boys in the neighbourhood they tease me for wearing the hearing aid....."

Students' reports also showed that hearing children their age were seen by them as unfriendly, clever and exploitative. A 14 years old boy stated, “They are clever children, I don't play with them anymore they fight so much."

Another 16 years old boy noted, "Normal people lie a lot, I play cricket with normal children at home and they keep telling me that I am out even when I am not, they set the rules and then cheat."

Two respondents noted that they thought others were talking about them. A 16 years old girl said, "I can tell when people are talking about me, where ever I go normal people are whispering in each other's ears about me.”

(C) The International Journal of Indian Psychology, ISSN 2348-5396 (e)| ISSN: 2349-3429 (p) | 120 


\section{The Unheard, the Unspoken, A Phenomenological View of Deafness}

\section{Teachers}

Students of all eight students reported that their students felt that they were disadvantaged; they thought they should be hearing. In some cases this feeling was very intense in other cases only a passing comment. Students suffered from problems in close neighbourhoods where their peers teased them or fought with them. In two cases the complaints were referred to the school b the parents in order to make the student understand not to run into trouble at home.

A teacher reported, "Normal children do not include them in their circles, nobody knows sign language and then these children feel left out. They have faced rejection so many times because of their disability that they do not want to try anymore. They frequently don't mingle with others now."

Teacher of a 16 years old student said, "His mother calls up to tell us that he fought over cricket at the playground and hit a boy. When we ask him he says the other boy cheated. We only tell him to be patient."

Teacher of another boy student said, "Whenever we ask them to write an essay about their future goals they have a desire to be something and in the end they conclude that they can't hear, it's sad to see that, once I asked him to write a similar essay and he had tears in his eyes at the end of the class, he feels disadvantaged and missing out on things.”

A teacher whose student had been mainstreamed and then returned to the same school told, "His parents tried putting him in a normal school, he did fine till grade four, he is very intelligent and one of the brightest students here, but in class five the problems started, the other students teased him a lot, break time was very hard for him there and he also started failing at school because of all that bullying by normal kids. So his parents sent him here again. He is happier now on being here, he never wants to go to a hearing kid's school again.”

\section{Social functioning \\ Students}

The theme formulated as a response to questions regarding general functioning at home such as going to the grocery store, or riding a bike or attending a party is identified as social functioning. Three male students reported that they were allowed to ride a bike, either alone and close to home or with a family member. Household chores that can be accomplished with considerable ease are allowed. A 14 years old boy said, "I am learning to ride a bike."

An 18 years old boy student with better speech said, "I ride a motorbike on my own, when I go to speech therapy my mother accompanies me, on Sunday mornings I can go to get breakfast all by myself."

Four of the students, including one girl child reported that they use mobile phone at home. They did not receive voice calls but used messaging services and also were on Social media networks where their only friends were not deaf but also hearing people. 


\section{The Unheard, the Unspoken, A Phenomenological View of Deafness}

One 14 years old boy reported, "I have a mobile phone and can message, I have normal friends I play cricket with and I use it to communicate with them.”

The three students who reported watching TV reported that they only watch Tom and Jerry since it can be understood clearly or movies with subtitles. One student reported in the absence of written subtitles he makes out the story on his own. News channels were also viewed and the written ticker is read to be informed cricket was also popular among boys.

A 14 years old boy told, "I enjoy watching cricket and Tom and Jerry. I can watch movies with my hearing aid on as well and when there are subtitles available..........Ii am not on the internet like the other boys, my father doesn't allow......... I am allowed to play videogames on play station instead."

A 16 years old girl reported, “I watch dramas on TV with my mother...........they don't have subtitles..... When my mother can’t explain the story I just imagine what’s going on.”

Of the eight students interviewed the response to the question how often do they go out or do they enjoy public spaces was a simple yes or no, however four students of these eight elaborated their experiences. Two of them enjoyed going out whereas others had stopped going due to the constant questions strangers asked their parents about their deafness and the shame and guilt they felt.

An 18 years old boy student reported, "I love going out, I also wish to travel to other cities such as Islamabad, even visit America....I often go to restaurants with my family and have never experienced teasing."

Another 13 years old boy student had a different experience, "I go out with my family, but people ask my parents about the hearing aid and show sympathy, I do not like that..... it makes me angry..... like staying at home.”

A boy student of 16 years old age stated, “I don't go out with my family any more...... am fed up of the questions and the pointing...... besides I don't understand what people around me are saying."

Both girls reported helping their mothers with the house work and not watching TV.

Three students reported playing cricket with normal people, but as is mentioned above their opinion of hearing people is not one of liking and their experience of playing with them is also mostly negative.

\section{Teachers}

Teachers were aware of the students social functioning beyond the classroom, since parents call them up frequently to discuss their child's performance. Teachers also conducted regular sessions with their students in an informal setting; students themselves were also comfortable with their teachers and referred to them as friends who understood them. Teachers held their own 


\section{The Unheard, the Unspoken, A Phenomenological View of Deafness}

opinions on how their students were treated at home and the ways in that had a trickledown effect in school.

Teacher of an 18 years old student said, "He has good speech, one of the best ones in school, but he still isn’t confident enough. Whenever we ask him to speak up in assembly he avoids it........ This confidence is developed at home and beyond.”

Teacher of a 16 years old boy student said, "Riding a motorbike has been both good and bad for him, he used to help his mother, but now it is an escape from home.....his mother doesn't know where he is...... it is dangerous because he has manipulative friends in the neighbourhood and his mother doesn’t want him to be friends with them but she can't keep him inside you know.”

On riding a bike teacher of a 14 years old boy student said, "He has started riding a bike now....which is a huge and a great development...his mother was very overprotective and we had to talk to her so many times to convince her.....he is a boy he will need to learn to do this.” Teacher of another 16 years old boy sad, "He wants to be friends with the boys in the neighbourhood so desperately that they exploit him most of the time. He has to spend money and tolerates bullying...... we have talked to him so many times.....but what can we do....boys his age need peers....those are all hearing kids and he gives in to all that....it shatters his confidence.”

Teacher of a 17 years old boy student said, "His parents have given him everything.....they have spoiled him.....he doesn't pay attention in school as much.....they don't learn sign language to guide him how to use that freedom......they overcompensate for his deafness.”

\section{Academic functioning}

\section{Students}

Most students loved mathematics and computers, the students interviewed were good at studies and were vigilant about their performance. One girl student was reported to have been getting low grades till the teachers found her a study partner and it helped her a lot. Languages appeared to pose a problem for majority of the students, when languages were liked it was mostly Urdu the native language the interested students. English and Urdu were both compulsory subjects and the students reported finding English essays too long. Teachers used visual aids for teaching and explaining concepts, students of higher classes studying sciences reported that the practicum was hard. A few students also took tuition academies after school. Their opinions and experiences are shared below.

An 18 years old student who also used to go to academy said, "I like computers, I am also fond of sciences but the practicum is difficult...... go to an academy too.....my classmates are hearing and all normal...." When asked if he were friends with them or asked them to explain 


\section{The Unheard, the Unspoken, A Phenomenological View of Deafness}

what he did not understand he said, "No......I keep to myself.....I don't ask the teacher to repeat......I try to figure it out on my own....or ask the teachers here at school the next day." A 13 years old boy student said, "I like maths....languages are hard to understand...... like law because my father is a lawyer.”

A 14 years old boy student reported, "I like Urdu, English is lengthy but I find it interesting as well.....Ii borrow books from the school library.....My mother encourages reading.......sometimes she comes and selects books for me too.”

Three students who were in senior classes wanted to make computers and graphic designing their field of choice as well.

\section{Teachers}

Teachers reported that the students are vigilant. They did however feel that the opportunities available to students after finishing school are scarce and skilled labour is hard to find. The school was associated with two fine arts departments of universities and another handicraft organisation for employment of the students later on. The school has also expanded and added a college section for awarding a bachelor degree since most of their students did not want to leave and mainstreaming had its hazards. The school also offers skill based diplomas in art and graphic designing and frequently holds orientation classes for parents and students, career counselling was also offered. Unfortunately, teachers added that the number of opportunities available is very limited.

Teacher of a 16 years old boy stated, "Using internet has helped him, he learns new words and asks us the meanings, he often comes to school with a vocabulary list and they also share that among themselves.”

Teacher of a 13 years old said, "He wants to be like his father, this depresses him a lot.....he wants to be a lawyer."

Teacher of a 16 years old girl reported, "They don't have a computer at home........she enjoys using it here.......her cousin is in the same school, she has partnered with her in studies now and has progressed considerably."

A 14 years old boy who used to go to a mainstream school said, "He has problems now coming to this school, he acquired deafness during early childhood and mixes up signs and language too often. This makes him lose marks at school, sometimes I think he sets the bar so high for himself."

An 18 years old boy who studied at an academy after school as well had his teacher saying this, “Going to the academy has not improved his grades in anyway....he doesn't ask if he doesn't understand anything......the academy is for hearing students only...... but the parents don't have any other options. He also plans on coming back here for college.......there aren't many facilities that would help or be inclusive. Only (names of two universities) accommodate these children and that too in fine arts." 


\section{The Unheard, the Unspoken, A Phenomenological View of Deafness}

\section{Coping skills \\ Students}

The last of the themes to be found in this study is coping. This refers to how the students have learnt to cope with the way they are treated due to deafness. This does not imply coping with deafness, since they are learning sign language and those who can wear hearing aids. Rather how they cope with deafness as a 'phenomenon' as a 'lived experience'. This theme was found in response to the questions related to their opinions of hearing community and how they treated them.

Students made use of problem and emotion focused coping methods, some displayed avoidant behaviours whereas others just learnt to go with the flow.

The categories within this theme are avoidance coping, offering explanations for deafness, hating the other person or wishing to be normal, bottled up anger and frustration as well as reliance on other close hearing friends was also found.

An 18 years old boy said, "I don't play with those boys anymore.....I get angry at them and leave the playground." A 17 years old boy had something similar to share, "Whenever we go out people ask questions.....I get angry but now I have learnt to tolerate....I don't interact with people and mind my own business.”

A 16 years old boy reported, "I get angry at the boys from my neighbourhood, they cheat on games and make fun of my hearing aid..... let it go....I know God is watching them and will be fair to me."

A 13 years old boy said, "Whenever we go out and people ask or anything my parents answer, I ignore those people."

Displaying patience when angry at the way people treated them was found to be common.

A 16 years old boy shared is experience, “Sometimes I get so angry at the way people don’t answer that I want to hit them....but I don't fight with anyone...there is no use.”

A 16 years old girl shared how she coped at home with her family members not sharing stories with her, "I keep to myself, and I keep reading my own books. I don’t ask for repetition from them.....most of the time they don't notice me so I am fin with it."

Another 17 years old girl said, "I wish I could hear so there won't be that many problems........whenever we go to a family function I sit quietly and watch.”

A 14 years old boy student reported, "The boys in my neighbourhood are friends, Ii have one close friend in particular and he usually helps me....he has learnt some of the signs as well.”

Another 16 years old boy reported, "I have friends and teachers here who explain things...they help me a lot. I hope when I go to (name of university) I find someone who could help as well.”

\section{Teachers}

A few teachers as explained above reported that the students had adjustment problems at home. The communication gap had led to defiance. Some students had positive coping mechanisms 
whereas some had negative. These with a positive coping mechanism had found friends at school and rather than being rejected by the hearing community have accepted the deaf community. One teacher stated, "When he came to this school he disliked it a lot....but with time he started being bullied by his other friends and he is in much better shape now...he learnt sign language and is coping well."

Another teacher said, "He used to get very angry and throw tantrums at home, we got frequent complaints. He also ran into fights with the neighbourhood children.....but now it is settling down....it isn't easy telling a child he is different but we tell him to have patience, those people are not going to change. He hates the hearing community for this reason, a number of the students in the school do not like being with hearing kids their age they make them angry."

Teacher of a 16 years old boy reported, "His friends make fun of his hearing aid, they keep telling him he doesn't look good with it on, so he doesn't use it at home anymore.....his functioning is deteriorating every day because of this."

On the other hand the teacher of 14 years old boy reported, "His mother keeps us up to date with his progress. His grandfather goes to the park with him....he keeps an eye on the other boys so he isn't bullied which is extremely good, when he plays cricket he takes the hearing aid off so it doesn't gets damaged but wears it otherwise....the boys in his neighbourhood are good to him."

A 16 years old girl's teacher reported, "She doesn't go out with family much anymore.......she keeps to herself."

Another teacher of an older boy student said, "He has been very anxious for the last few months...he hopes he finds a helpful student at university, we want to same for him. He goes to the academy after school but has not made any friends with any of the normal hearing kids.....I wonder how he will cope there. I wish it is good for him, he caves in too quickly."

One of the teachers shared her insight, "When people ask those questions about the hearing aid and stare at them they don't understand that these children understand everything, they are as intelligent as other people their age..... Such behaviours simply shatter their self-esteem. Most of the time we have to battle with their low self-esteem so much that even we prefer they don't interact with the hearing community, I haven't witnessed experiences that would make me optimistic."

Teacher of a 16 years old boy stated, "He is frustrated and angry most of the time....we try to make him understand that the people around him aren't mean they are just ignorant....but naturally he can't agree. The hearing kids are a majority and even if he picks a fight he gets beaten up.”

\section{DISCUSSION}

Relations with deaf community are based on shared identity; Deaf. Identification with Deaf is a factor which mediates social functioning and is a source of support. Close ties within the Deaf community provides a reservoir of energy and motivation to people who live with deafness. Padden and Humphries, authors of the phenomenal work on Deaf in America after in-depth research also conclude that Deaf is a shared culture. This particular characteristic defines a 


\section{The Unheard, the Unspoken, A Phenomenological View of Deafness}

separate culture, so much so that it becomes the perfect fit for ethnic and minority studies (Padden \& Humpheries, 2005). Children who identify with Deaf are at an advantage that culminates into healthy growth as responsible people who are comfortable with their identity.

However, as noted by Padden and Humphries, children who undergo cochlear implants are viewed as hearing people and this obstructs their chances of growth and bilingualism (Padden \& Humpheries, 2005). In the current study as well children who did not like Deaf community were those who were stressed to learn spoken language and had an average functioning of speech. Also they could not perfectly identify with any one culture.

Individual differences and personality characteristics also affect ones interpersonal relationships and outlook towards society. In certain cases where Deaf was not preferred such could be the case. Nonetheless, analysis of the students' interviews along with teacher's opinion did not reveal any such clear cut differences or any other factor to which the choice could be attributed. Moreover, research suggests that extent of deafness plays a role in individual's integration with Deaf community. In cases where hearing or speech is better deaf identity development is also different, with most cases identifying more with hearing community (Fischer \& McWhirter, 2001).

If the individual is pulled in different directions, i.e.; hearing, speaking on one side and sign language on the other, problems arise. Family expectations as will be noted below cause mixed signals in children. Diversity in the community should be respected and understood. It has been noted that Deaf is a community frequently marginalized and endangered due to the majorities manipulation of rights and liberties (McKee, Thew, \& Schlehofer, 2013). Moreover, deafness is viewed as a disability and not as diversity, a belief which is the core problem in community's perception of Deaf and related ideas.

Research suggests that maternal language and interaction is of significance to child development. It affects the child's socio-emotional development, reading skills and interaction. It is also found to be essential that parents learn their child's language and not let that become a barrier (Weaver \& Starner, 2011). Communication is a two way process. Both participants bring something different and unique to the communication process. Such a communication builds to be a 'dyadic communication'. According to one view in dyadic communication, not only the verbatim but also 'energy' is communicated between people (Almore, 1979). With everyone in the dyad bringing to the relationship preconceived ideas and emotions. These emotions are perceived as progressive or debilitating. Basis of these are previously held beliefs generated as a result of experiences.

If this process is analysed from a sociological perspective it does not fall short of 'language imperialism' or a part of the 'language game theory'. Despite these terms having a political connotation, it is the perfect fit to communication patterns Deaf face. Spoken language is 


\section{The Unheard, the Unspoken, A Phenomenological View of Deafness}

replacing their language of communication at home, with families interested in learning only as much as is necessary for their own motives. This kind of behaviour causes clear cut differences that culminate into other patterns of behaviour on the part of the participants. According to language game theory, it is also interpreted as a marginalization of ethnic minorities as well as domination; it tips the scales of power equilibrium (Laitin \& D, 1993), with parents in the dominant power and their children merely subordinates. The effects of this social fact are a few. One effect found to be similar across all participants is 'the teacher as confidant'. Teacher fills the void Deaf students feel by a lack of communication at home. Teachers are trained in the use of sign language, a factor essential to Deaf and disappointingly missing at home.

It is also recorded that interactional dominance does not mean being in power over the communication dyad (Linell, Gustavvson, \& Juvonen, 1988). Differences in interaction and reactions are also somewhat a direct result of the territory taken by one person during meaningful interactions. Low response in Deaf children has been found by research but the causal factor is language and not intelligence. It has also been established that speech therapy causes a unique bond in families because it helps in integration rather than enhancing diversity (Bat-Chava \& Martin, 2002). Though this finding and relevant research are both phenomenal a fact that should not be undermined is that speech therapy may not be effective for all deaf children and in some it may be a stressor.

One surprising and disturbing finding at the same time is the perception of Hearing people by Deaf. The best explanation for these differences and perception lies in the social psychology concept of us vs. them. In-group and out-group boundaries are clearly demarcated. Language is the driving force in unity and diversity, along with shared ethnicity, religion, customs and traditions. In this case the criterion is simply language (Giles \& Giles, 2011). Groups can also be based on shared interests but when majority group members persecute or hold prejudice against minority members problems arise. Same is the case with Deaf and Hearing. Clinging to in-group values is also a means to play off out-group members, an act that helps safeguard self-esteem. Language is the archaic determinant of in-group identification (Giles \& Giles, 2011). Hence, hatred on hearing community is based on their priori experiences with hearing people.

Literature related to this did not entirely support the findings. Research about social functioning of Deaf in less developed countries is lacking and those of developed countries have a social functioning at par with hearing communities whereas the limited avenues and resources available to Deaf in LDC is unique to itself. One look at the literature provides a very distinct view. Deaf have their own community and culture: they are not limited by telecommunication technology in the North. Devices and resources are made to fit their needs. One newspaper reports covering

Bristol deaf centre $125^{\text {th }}$ year of progress, the report has covered all activities that the centre provides. Deaf do not have to look beyond their differences in order to fit in; they have their own 


\section{The Unheard, the Unspoken, A Phenomenological View of Deafness}

activities and a community that shapes them as versatile individuals (The Bristol Post, 2009). Much the same as the privileges provided to hearing students in Pakistan.

Technology is used among Deaf people and is made to fit their needs as sign language users. Also their ability to be bilingual with one spoken language helps their use of technology but this is in no way the determining factor. University students have used technology and social media much the same as hearing people to get themselves heard, to galvanize protests in favour of their rights (Brock \& Farell, 2006). Moreover video blogs are also created that help Deaf communicate with each other and find people of their community with similar interests. 'Vlogging' is a term coined for this specific reason, it means video blogs: a form of communication that uses video on blogs with content signed by sign language users, this has evolved in light of users' needs for communication in their own language rather than forced use of spoken or written languages that could endanger Deaf existence on the virtual networks. This has even created a new dimension to sign language on screen that helps understand meaning according to screen formatting and direction of sign relevant to screen (Hibbard \& Fels, 2011).

Use of web services in Deaf people is high in other parts of the world, where they use the web to communicate their feelings and to share existence. Blogs have been found to be a source of motivation, unity and a platform for advocacy for social justice among users. Research evidence suggests that written language fluency is as good in Deaf users as in hearing people (Hamill \& Stein, 2011). Marginalising a community based on differences that the majority view as a disability is unique to the participants of this research, a fact that has more of a regional cause than a universal one. In no way can the fact found in the current research be backed by literature available, neither can the teachers underlying concept of limiting Deaf children to course books out of the idea that they cannot understand difficult or varied vocabulary be justified.

In an equality focused community, police is also trained in the use of Sign language in order to help people communicate their problems and to enhance the services provided by the justice system. An important source used for police in these cases is the video-taping of complaints and verdicts such that Deaf can function equally in the community (The Bristol Post, 2011). Use of technology for equality is prevalent in other parts of the world. Moreover integrating the deaf and hearing communities is also a unique function being performed by the help of relay system. A device that puts an end to the deaf-deaf and hearing-hearing communication, it makes possible deaf-hearing communication. The device called 'Telecommunications Device for The Deaf' integrates users belonging to both languages. It works on a relay system if one user signs the interpreter translates it into written message or a spoken message and vice versa (Kukich, 1992). Hence in no way is telecommunication an obstacle for Deaf people.

Use of telecommunication or studying course material should not be the only pastime, as was the case with subjects of current research. A variety of hobbies and talents can be built in children 


\section{The Unheard, the Unspoken, A Phenomenological View of Deafness}

who belong to the Deaf community. The use of motorbike which caused problems in participants can also be a source of bonding between parents and their children. Motor sports have been noticed to be a bonding factor not one causing discord necessarily (Sophie, 2013).

Cultivating skills that can be managed without written or oral communication serve as a bonding factor at home and also a source of personality development for children with deafness. It can also be an asset for children later in life. Rather than finding out interests with the use of computer and being distant with family, family members can pay a crucial role in the development of Deaf members into holistic well-rounded personalities. In one case study, signing up for a pottery class and using pottery making as a resource for community interaction as well as a skill along with a unifying factor for family integration has been phenomenal (Prouty, 2005).

Theatre is a source of empowerment for Deaf (Mandell, 2013). It also helps them voice their experiences as well as find a niche in a predominantly hearing world. Such stories and experiences provide a riveting insight into the possibilities for integration and development of the civil society. In France theatre of Deaf people is two hundred years old, it not only builds bridges between diverse populations but also create collaboration between people that help communities progress in the appropriate direction (Aicardi, 2009).

Television viewing has also been found to be high among deaf users. In the current research as well television viewing was a constant across all participants. Interestingly the least sources of help are also available to people who watch the most T.V. According to one research deaf watch more hours of TV than their hearing counterparts. Surprisingly the choices of shows viewed are narrow; the programs preferred are adventure sports and movies. Programs that provide close captioning are not preferred (Austin, 1980). Facts that can be of help in the current research, content that provides subtitles or mute cartoons are enjoyed.

The most effective coping strategy is identifying with the deaf community. It also helps enhance self-esteem. The higher the identification with deaf community the higher is the individual's selfesteem and the varied the coping responses (Jambor \& Elliott, Self-esteem and Coping Strategies among Deaf Students, 2005).

Research also suggests that when it comes to play, the cards are in the favour of the hearing since they set the rules. Also in this case the hearing impaired child has to break the ice and help peers understand his differences, after which the hearing help and let him play (Bat-Chava \& Martin, 2003). The game depends upon this simple fact and acceptance of the hearing community.

According to the 'communication accommodation theory' of social Psychology either convergence or divergence occurs (Giles \& Giles, 2011). Where students had one or two insiders in the hearing community, convergence is taking place. The out-group in this case the hearing community is collaborating with Deaf and a reciprocation of feelings is evident. 
Frustration, resignation and isolation have been found to be the frequent coping methods against discrimination made use of by deaf people (Stacey \& Maynard, 2009). Deaf who are raised in an all hearing world often have coping difficulties when in peers. They often feel left-out and have a sense of being different. They also have missing information problems during work or play which causes estrangement and isolation (Bain, Scott, \& Steinberg, 2004). The current research points in a similar direction as well.

As noted in the current research, external attribution vs. internal attribution, disengagement vs. striving and group identification vs. disidentification all are forms of reactions to stigmatization (Major \& O'Brien, 2005). Deafness in the realm of social psychology is interpreted as a stigma in the hearing society that frequently discriminates against its members. Hence the current model is in agreement with 'involuntary responses to identity threat theory'.

\section{CONCLUSION}

Overall, the participants of this research displayed similar emotions and interpretations of the world they live in, they also hold almost similar thoughts about the hearing community. Coping mechanisms are fairly shared as well, though isolation or ignoring can be helpful for a short while, it creates further debilitating feelings and low self-esteem in the long run. The deaf community interviewed is not the only ones that feels this way. The teachers also concur. The pressure from family to 'fit in' is high on the children, especially since parent-child communication remains low. Some students can find outlets to vent their energy however productive means are largely absent. Hostility towards hearing community in general, the ones who exist beyond the school, is a shared phenomenon as well. Resources and social activities or avenues are scarce, which is one of the reasons bullying and name-calling is taken lying down. To gain further insight into 'deafness' an ethnographic research should be conducted. In light of current findings the hearing community can be called responsible for a number of disadvantages faced by Deaf. Parents need to make effort for learning sign language, most children crave for their parents love and attention and low communication leaves them in despair. Integrative technological devices should be available to help the deaf achieve an equal status in the society. In light of advancement of mobile networks internet facility, application catering to Deaf shall be introduced as a social measure. Inclusive education in cases where oral communication is possible shall be advocated and facilitated, for which a larger and broader social change as well as tolerance would be needed. A cross culture study into coping strategies needs to be conducted, adhering to the viewpoint that deaf is a culture. Indigenous systems for promoting equality are much needed. Most of the teachers added that their previous students had taken jobs which did not meet their skills only because that was all that was available, survival beyond school is another matter and it is usually just as hard Deaf is a culture, some differences may be present owing to the cultural differences between the participants and the researcher. Limited indigenous research is available whereas the statistics of deaf population suggest an increase with millions suffering in silence. 


\section{Acknowledgments}

The author appreciates the help and support offered by student and staff of Hamza Foundation for Deaf, as well as all others who facilitated the research process.

\section{Conflict of Interests}

The author declared no conflict of interests.

\section{REFERENCES}

Ahmad, W. I., Atkin, K., \& Jones, L. (November, 2002). Being deaf and being other things: young Asian people negotiating identities. Journal of Social Science \& Medicine, 55(10), 1757-1769.

Aicardi, C. (2009). The Analytic Spirit and the Paris Institution for the Deaf-Mutes, 1760-1830. History of Science, 47(2), 175-221.

Aicardi, C. (2009). The Analytic Spirit and the Paris Institution for the Deaf-Mutes, 1760-1830. History of Science, 47(2), 175-221.

Almore, M. G. (1979). Dyadic Communication. American Journal of Nursing, 1076-1078.

Almore, M. G. (1979). Dyadic Communication. American Journal of Nursing, 1076-1078.

American Speech-Language Hearing Association. (2011). Type, Degree and Configuration of Hearing Loss. ASHA.

American Speech-Language Hearing Association. (2011). Type, Degree and Configuration of Hearing Loss. Rockville: ASHA.

Asif, M. (August, 2008). Difficulties faced by deaf students and their interaction partners during interaction in inclusive secondary classrooms. Retrieved from http://core.roehampton.ac.uk/repository/content/subs/P.SIMONS/P.SIMONS299/Final\% 20Dissertation\%20by\%20Muhammad\%20Asif.pdf

Austin, B. A. (1980). The deaf audience for television. The Journal of Ccommunication, 30(2), 25-30.

Austin, B. A. (1980). The deaf audience for television. The Journal of Communication, 30(2), 25-30.

Bain, L., Scott, S., \& Steinberg, A. G. (2004). Socialization Experiences and Coping Strategies of Adults Raised Using Spoken Language. Journal of Deaf studies and Deaf education, 9(1), 120-128.

Bain, L., Scott, S., \& Steinberg, A. G. (2004). Socialization Experiences and Coping Strategies of Adults Raised Using Spoken Language. Journal of Deaf studies and Deaf education, 9(1), 120-128.

Bat-Chava, Y., \& Martin, D. (2002). Sibling Relationships of Deaf Children: The Impact of Child and Family Characteristics. Rehabilitation Psychology, 47(1), 73-91.

Bat-Chava, Y., \& Martin, D. (2002). Sibling Relationships of Deaf Children: The Impact of Child and Family Characteristics. Rehabilitation Psychology, 47(1), 73-91.

Bat-Chava, Y., \& Martin, D. (2003). Negotiating deaf-hearing friendships: coping strategies of deaf boys and girls in mainstream schools. Child: Care, Health \& Development, 29(6), 511-521. 
Bat-Chava, Y., \& Martin, D. (2003). Negotiating deaf-hearing friendships: coping strategies of deaf boys and girls in mainstream schools. Child: Care, Health \& Development, 29(6), 511-521.

Bauman, S., \& Pero, H. (2011). Bullying and Cyberbullying Among Deaf Students and Their Hearing Peers: An Exploratory Study. Journal of Deaf Studies and Deaf Education, 16(2), 236-253.

Braden, J. P. (2000). Deafness and Hearing loss. In A. E. Kazdin, Encyclopedia of Psychology (Vol. 2, pp. 441-444). Washington DC: American Psychological Association.

Braden, J. P. (2000). Deafness and Hearing loss. In A. E. Kazdin, Encyclopedia of Psychology (Vol. 2, pp. 441-444). Washington DC: American Psychological Association.

Bristol, T. i. (7 March, 2009). Bristol deaf centre marks 125 years of progress. The Bristol Post, p. 8.

Brock, R., \& Farell, E. F. (2006). Technology and Influential Blogs Helped Galvanize Protests at Gallaudet. Chronicle of Higher Education., 53(12), 40.

Brock, R., \& Farell, E. F. (2006). Technology and Influential Blogs Helped Galvanize Protests at Gallaudet. Chronicle of Higher Education., 53(12), 40.

Bukatko, D., \& Daehler, M. W. (2004). Child Development: a thematic approach. New York: Houghton Mifflin Company.

Charlson, E., Strong, M., \& Gold, R. (1992). How Successful Deaf Teenagers Experience and Cope With Isolation. American Annals of the Deaf, 137(3), 261-270.

Creswel, J. W. (2007). Qualitative Inquiry research Design: Choosing Among Five Approaches (2nd ed.). California: Sage.

Creswell, J. C. (2006). Qualitative inquiry and research design. Los Angeles: SAGE.

Fatima, G., \& Malik, M. (May, 2015). Problems Faced by Special Education Teachers in Teaching Mathematics to Students with Deafness. Academic Research International, 6(3), 3-22.

Fischer, L. C., \& McWhirter, J. J. (2001). The Deaf Identity Development Scale: A Revision and Validation. Journal of Counseling Psychology, 48(3), 355-358.

Fischer, L. C., \& McWhirter, J. J. (2001). The Deaf Identity Development Scale: A Revision and Validation. Journal of Counseling Psychology, 48(3), 355-358.

Giles, H., \& Giles, J. (2011). Ingroups and Outgroups. In H. Giles, \& J. Giles, Social Psychology (pp. 141-162). New York: Sage.

Giles, H., \& Giles, J. (2013). Ingroups and Outgroups. In A. Kurylo, Inter/Cultural Communication (pp. 141-162). New York: Sage.

Hamill, A. C., \& Stein, C. H. (2011). Culture and Empowerment in the Deaf Community: An Analysis of Internet Weblogs. Journal of Community \& Applied Social Psychology, 21, 388-406.

Hamill, A. C., \& Stein, C. H. (2011). Culture and Empowerment in the Deaf Community: An Analysis of Internet Weblogs. Journal of Community \& Applied Social Psychology, 21, 388-406.

Hardonk, S., Desnerck, G., \& Loots, G. (2011). From Screening to Care: A qualitative analysis of the parental experiences related to screening and rehabilitation care for children with congenital deafness in Flanders, Belgium. The Volta Reveiw, 299-324. 


\section{The Unheard, the Unspoken, A Phenomenological View of Deafness}

Hardonk, S., Desnerck, G., \& Loots, G. (2011). From Screening to Care: A qualitative analysis of the parental experiences related to screening and rehabilitation care for children with congenital deafness in Flanders, Belgium. The Volta Reveiw, 299-324.

Hessy Biber, S. N., \& Leavy, P. (2011). The practice of qualitative research. Los Angeles: SAGE.

Hibbard, E. S., \& Fels, D. I. (2011). The vlogging phenomena: a deaf perspective. The proceedings of the 13th international ACM SIGACCESS conference on Computers and accessibility (pp. 59-66). New York: ASSETS.

Hibbard, E. S., \& Fels, D. I. (2011). The vlogging phenomena: a deaf perspective. The proceedings of the 13th international ACM SIGACCESS conference on Computers and accessibility (pp. 59-66). New York: ASSETS.

Hintermair , M. (2006). Parental Resources, Parental Stress, and Socioemotional Development of Deaf and Hard of Hearing Children. Journal of Deaf Studies and Deaf Education , 11(4), 493-513.

Jambor, E., \& Elliot, M. (2005). Self-esteem and Coping Strategies among Deaf Students. Journal of Ddeaf Studies and Deaf Education, 10, 63-81.

Jambor, E., \& Elliott, M. (2005). Self-esteem and Coping Strategies among Deaf Students. Journal of Deaf studies and Deaf education, 10(1), 63-81.

Jambor, E., \& Elliott, M. (2005). Self-esteem and Coping Strategies among Deaf Students. Journal of Deaf studies and Deaf education, 10(1), 63-81.

Kukich, K. (1992). Spelling corrections for the telecommunications network for the Deaf. Computers and people with disabilities, 35(5), 80-90.

Kukich, K. (1992). Spelling corrections for the telecommunications network for the Deaf. Computers and people with disabilities, 35(5), 80-90.

Laitin, D., \& D. (1993). The Game Theory of Language Regimes. International Political Science Reveiw, 14(3), 227-239.

Laitin, D., \& D. (1993). The Game Theory of Language Regimes. International Political Science Reveiw, 14(3), 227-239.

Lillemor, R., Hallberg, M., \& Carlsson, S. G. (1991). A qualitative study of strategies for managing a hearing impairment. British Journal of Audiology, 25(3), 201-211.

Linell, P., Gustavvson, L., \& Juvonen, P. (1988). interactional dominance in dyadic communication: a ppresentation of Initiative-response analysis. Linguistics, 415-442.

Linell, P., Gustavvson, L., \& Juvonen, P. (1988). Interactional dominance in dyadic communication: a presentation of Initiative-response analysis. Linguistics, 26(3), 415-442.

Luckner, J. L., \& Stewart, J. (2003). Self-Assessments and Other Perceptions of Successful Adults Who Are Deaf: An Initial Investigation. American Annals of the Deaf, 148(3), 243-250.

Major, B., \& O'Brien, L. T. (2005). The social psychology of stigma. Annual Review of Psychology, 56(1), 393-421. 
Major, B., \& O'Brien, L. T. (2005). The social psychology of stigma. Annual Review of Psychology, 56(1), 393-421.

Mandell, J. (2013). The Circle of Inclusion. American Theatre, 30(5), 66-69.

Mandell, J. (2013). The Circle of Inclusion. American Theatre, 30(5), 66-69.

McKee, M., Thew, D., \& Schlehofer, D. (2013). Ethical Issues in Conducting Research With Deaf Populations. American Journal of Public Health, 103(12), 2174-2178.

McKee, M., Thew, D., \& Schlehofer, D. (2013). Ethical Issues in Conducting Research With Deaf Populations. American Journal of Public Health, 103(12), 2174-2178.

McLeod, J. (2001). Qualitative Research in Counselling and Psychotherapy. London: Sage.

Moeller, M. P. (2000). Early Intervention and Language Development in Children Who Are Deaf and Hard of Hearing. Pediatrics, 106(3), 43.

Mugeere, A. B., Atekyereza, P., Kirumira, E. K., \& Hojer, S. (2015). Deaf identities in a multicultural setting: The Ugandan context. African Journal of Disability, 4(1), 69-78.

Nortey, D. A. (13 March, 2009). Barriers to social participation for the deaf and hard of hearing in Ghana. Retrieved from The University of Bergen Web site: http://hdl.handle.net/1956/3180

Padden, C., \& Humpheries, T. (2005). Inside Deaf Culture. Cambridge, MA: Harvard University Press.

Preisler, G., Tvingstedt, A. L., \& Ahlström, M. (2002). A psychosocial follow-up study of deaf preschool children using cochlear implants. Journal of Child Care, Health and Development, 28, 403-418.

Preisler, G., Tvingstedt, A.-L., \& Ahlstrom, M. (2005). Interviews With Deaf Children About Their Experiences Using Cochlear Implants. American Annals of the Deaf, 150(3), 260-267.

Prouty, M. (2005). Welcome to my world. Ceramics Monthly, 53(3), 124-128.

Prouty, M. (2005). Welcome to my world. Ceramics Monthly, 53(3), 124-128.

Safder , M., Muhammad, M., Akhter, S., Fatima, G., \& Malik, M. (December, 2012). Problems Faced by Students with Hearing Impairment in Inclusive Education at the University Level. Journal of Research and Reflections in Education, 6(2), 129 -136.

Sophie, E. (3 May, 2013). Prized motocross bikes belonging to dad and daughter stolen in raid. Derby Evening Telegraph, p. 17.

Sophie, E. (3 May, 2013). Prized motocross bikes belonging to dad and daughter stolen in raid. Derby Evening Telegraph, p. 17.

Stacey, B., \& Maynard, D.-M. (2009). In Their Own Words: Exploring the Phenomenological Field of a Sample of Employed Persons Who Are Deaf in Barbados. International Journal of Disability Management Research, 4(1), 12-18.

Stacey, B., \& Maynard, D.-M. (2009). In Their Own Words: Exploring the Phenomenological Field of a Sample of Employed Persons Who Are Deaf in Barbados. International Journal of Disability Management Research, 4(1), 12-18.

The Bristol Post. (7 March, 2009). Bristol deaf centre marks 125 years of progress. The Bristol Post, p. 8. 
The Bristol Post. (10 May, 2011). Police target services at the deaf community. The Bristol Post, p. 25.

Weaver, K. A., \& Starner, T. (2011). We Need to Communicate! Helping Hearing Parents of Deaf Children Learn American Sign Language. Dundee: ASSETS.

Weaver, K. A., \& Starner, T. (2011). We Need to Communicate! Helping Hearing Parents of Deaf Children Learn American Sign Language. The proceedings of the 13th international ACM SIGACCESS conference on computers and accessibility (pp. 91-98). Dundee: ACM.

William, C. (2011). Theories of Development: Concepts and Applications (6th ed.). NJ: Pearson.

William, C. (2011). Theories of Development: Concepts and Applications . NJ: Pearson.

Wooten, P. M. (April, 2014). A phenomenological study of online learning for deaf students in postsecondary education: a deaf perspective. Retrieved from Liberty University : http://digitalcommons.liberty.edu/cgi/viewcontent.cgi?article=1880\&context=doctoral

World Health Organization. (2012). WHO global estimates on prevalence of hearing loss. WHO.

World Health Organization. (2012). WHO global estimates on prevalence of hearing loss. Geneva: WHO.

Young, A., \& Hunt, R. (2011). Research with d/Deaf people. London: National Institute for Health Research.

Young, A., \& Hunt, R. (2011). Research with d/Deaf people. London: National Institute for Health Research.

How to cite this article: I Maqbool (2016), The Unheard, the Unspoken, A Phenomenological View of Deafness, International Journal of Indian Psychology, Volume 3, Issue 4, No. 65, ISSN 2348-5396 (e), ISSN: 2349-3429 (p), DIP: 18.01.145/20160304, ISBN: 978-1-365-34680-4 